\title{
PEMANFAATAN PMT KOPEL SEBAGAI SARANA PENGALIHAN BEBAN DI GARDU INDUK SAYUNG KABUPATEN DEMAK
}

\author{
Binka Aji Wibowo, Saiful Manan \\ Program Studi Diploma III Teknik Elektro \\ Fakultas Teknik Universitas Diponegoro
}

\begin{abstract}
Binka Aji Wibowo, Saiful Manan, in paper use PMT coupling as load transfer in Sayung District Substation, Demak explain that to meet the reliability of the distribution system, it is necessary to do a continuity in the distribution of electrical energy. There are various causes of outages ranging from maintenance to interference. To resolved these problems, there are several solutions that can be done, such as transfer transformer load through PMT coupling. This can be done by connecting the two busbars by using a PMT. In operation the PMT coupling need to do prior preparation, among others, the daily load calculations. It is intended to carry transformer load does not exceed setting value.
\end{abstract}

Keywords : PMT coupling, Busbar, Transformer.

\section{PENDAHULUAN}

Demi meningkatkan keandalan dalam kontinuitas penyaluran energi listrik maka perlu adanya strategi yang digunakan agar tidak terjadi pemadaman apabila dilakukan pemeliharaan maupun gangguan yang terdapat pada trafo 150/20 KV dan perlengkapannya. Salah satu upaya yang dapat dilakukan yaitu memasang PMT kopel pada trafo dua dan tiga Gardu Induk Sayung. Pemasangan PMT kopel dapat meningkatkan kontinuitas penyaluran energi listrik baik pada trafo dua maupun trafo tiga, hal ini dikarenakan PMT kopel dapat menghubungkan kedua buah busbar tersebut, sehingga beban dari salah satu trafo dapat di alihkan pada trafo yang lain.

Akan tetapi dalam melakukan pemasukan PMT Kopel di haruskan melakukan parallel sesaat trafo 150/20 KV. Oleh karena itu diharuskan melakukan perhitungan beban yang terdapat pada beban yang akan di limpahkan dan trafo yang akan di beri limpahan, selain itu ada berbagai persayaratan lain yang harus di penuhi apabila melakukan pelimpahan dengan menggunakan PMT Kopel.

\section{PEMANFAATAN PMT KOPEL SEBAGAI PELIMPAHAN BEBAN}

Demi menjaga keandalan sistem distribusi $20 \mathrm{kV}$ maka perlu dilakukan upaya dalam menjaga kontinuitas penyaluran energi listrik. Ada duacara untuk menjaga kontinuitas penyaluran energi listrik yaitu dengan cara melakukan pengalihan beban dengan melakukan manuver jaringan atau dengan melakukan pengalihan beban dengan menggunakan PMT kopel.

\section{Kubikel 20 KV}

Dalam pengoperasianya kubikel berfungsi sebagai pengendali circuit yang dilakukan oleh saklar utama sehingga dapat memadamkan jaringan apabila akan dilakukan pekerjaan pada jaringan.
Selain itu kubikel juga berfungsi sebagai pembagi jaringan sehingga apabila terjadi gangguan pada suatu penyulang maka gangguan tersebut tidak meluas pada penyulang yang lain.

\section{Compartemen Rell}

Berfungsi sebagai tempat kedudukan busbar/rell. Dilengkapi dengan isolator penyangga yang berfungsi untuk menyangga kedudukan rell agar kuat.

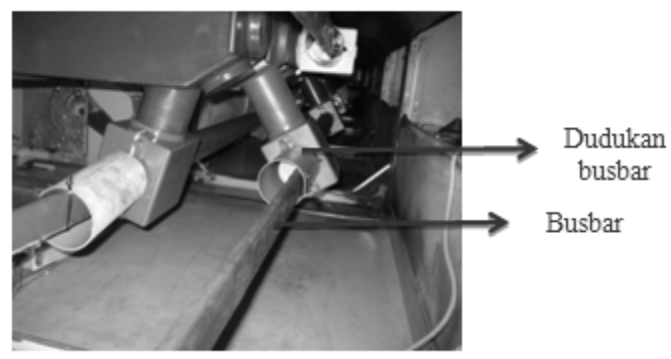

Gambar 1. Rell Kubikel

Compartemen Lemari Control

Berfungsi sebagai pusat terminal kontrol, sumber DC dan peralatan pendukung seperti Ampermeter, Relai Proteksi, Kwhmeter tombol close/open dan juga pusat wirring control.

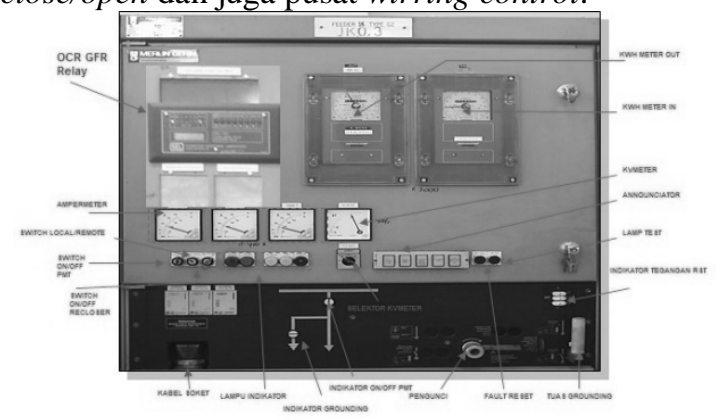

Gambar 2. Kompartemen Low Voltage 


\section{Pemisah Rell}

Berfungsi untuk membuka dan menutup aliran listrik tanpa beban. Kontak penghubung Pemisah Rell tidak dilengkapi dengan media peredam busur api.

\section{Pemutus Tenaga (PMT)}

Berfungsi untuk membuka dan menutup aliran listrik dalam keadaan berbeban atau tidak berbeban, termasuk memutus pada saat terjadi gangguan hubung singkat. Kontak penghubung PMT dilengkapi dengan media peredam busur api.

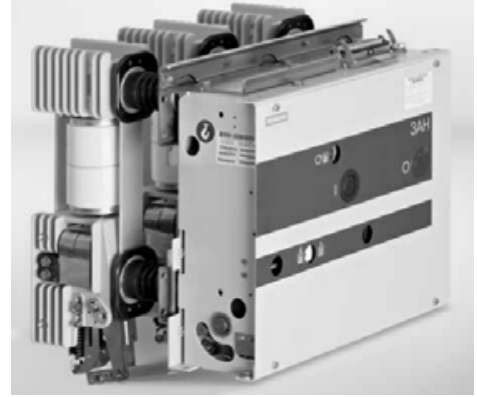

Gambar 3. Set Pemutus Tenaga

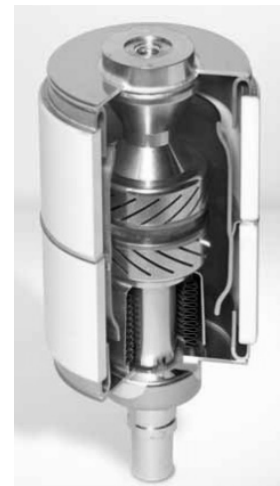

Gambar 4. PMT Vaccum

Closing Coil berfungsi menggerakkan mekanik untuk menghubung kontak utama PMT, sedangkan trippingcoil berfungsi menggerakkan mekanik untuk membuka kontak utama PMT. Motor berfungsi untuk mengisi pegas/spring charge mekanik PMT yang siap dieksekusi tripping coil. Motor dalam PMT ada yang sumber powernya AC $220 \mathrm{~V}$ atau ada juga yang menggunakan DC $110 \mathrm{~V}$.

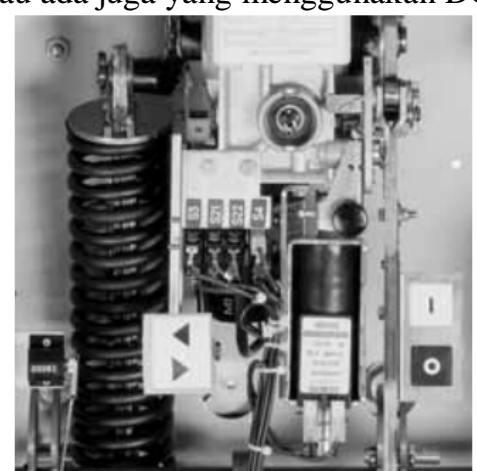

Gambar 5. Mekanik PMT

\section{Pemisah Kabel}

Berfungsi untuk membuka dan menutup aliran listrik tanpa beban, dan kontak hubung pemisah kabel tidak dilengkapi dengan media peredam busur api.
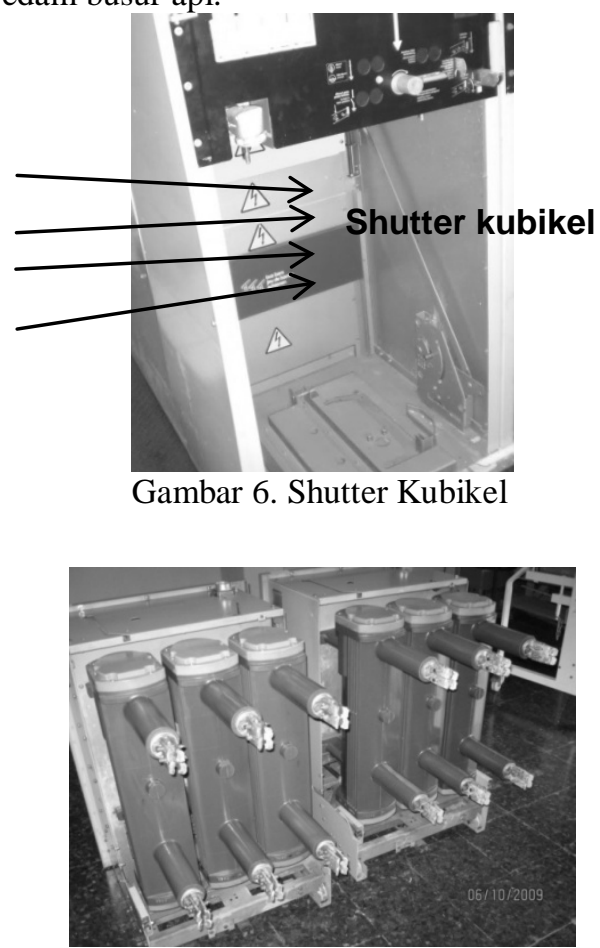

Gambar 7. Kontak Hubung Pemusah Kubikel

\section{Compartemen Kabel}

Sebagai ruang tempat kedudukan cabel in door.

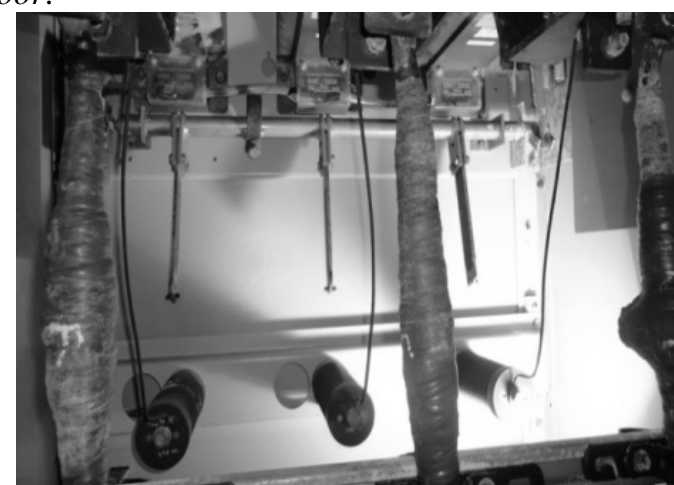

Gambar 8. Kabel Power Pada Kubikel

\section{Trafo Arus (CT)}

Trafo Arus (CT) merupakan alat pendukung yang digunakan dalam instalasi Gardu Induk Sisi 20KV. Alat ini untuk mendukung dalam pengukuran arus yaitu sebagai pengukuran dan sebagai proteksi terhadap arus lebih. Current transformer digunakan untuk Mentransformasikan besaran arus dari nilai arus yang besar ke arus yang kecil digunakan untuk pengukuran dan proteksi. Arus primer ke arus sekunder yang digunakan untuk pengukuran yaitu Ampermeter dan KWhmeter serta untuk proteksi yaitu relay proteksi, 
elain itu juga digunakan sebagai isolasi antara sisi tegangan yang diukur/diproteksi dengan alat ukurnya atau alat proteksinya.

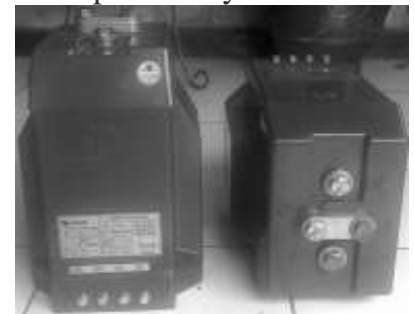

Gambar 9. Trafo Arus (CT)

\section{Pemanas (Heater)}

Merupakan alat pemanas berfungsi untuk memanaskan ruang terminal kabel dalam kubikel agar kelembabannya terjaga.

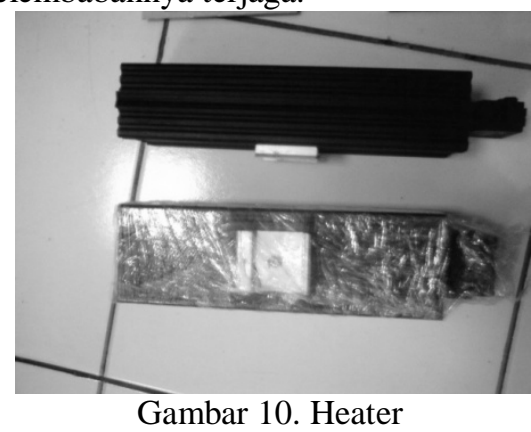

Keadaan ini diharapkan dapat mengurangi efek corona pada terminal kubikel tersebut.Corona akan menyebabkan turunnya kualitas isolasi/breakdown peralatan. Sehingga apabila ada kenaikan tegangan/arus akibat gangguan, maka titik lemah dari isolasi ini akan terancam untuk rusak/meledak/terbakar.

PMT Kopel

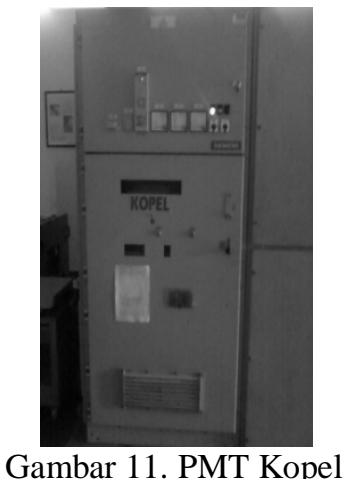

Pada Kubikel kopel dilengkapi dengan berbagai perlengkapan antara lain:

- Pemutus beban

- $\quad$ Metering

- Relay Proteksi

- Trafo Arus

Dikarenakan pada PMT kopel menghubungkan dua buah busbar, sehingga membutuhkan PMT dengan arus nominal di atas 2000 A. Pengaplikasiannya di lapangan biasanya menggunakan kubikel $24 \mathrm{kV}$ dengan kapasitas 2500 A. kubikel ini juga digunakan pada kubikel incoming. Selain menggunakan PMT dalam mengkopel busbar diperlukan interface busbar dengan kabel power yang digunakan untuk menghubungkan kabel power keluaran PMT dengan busbar yang lain.

PMT kopel sendiri tidak dapat sepenuhnya digunakan sebagai peralatan proteksi, karena setting relay yang menyulitkan sehingga fungsi proteksinya tidak dapat selalu berhasil. Hal ini di sebabkan waktu tunda pada setting relay harus di atas nilai penyulang dan di bawah incoming, sedangkan waktu tunda maksimal yaitu 0.3 detik. Sehingga apabila terjadi gangguan pada busbar yang sedang dialihkan bebannya maka PMT kopel tidak dapat bekerja dengan baik.

\section{Transformator Tenaga}

Transformator adalah suatu alat listrik yang dapat memindahkan dan mengubah energi listrik dari satu atau lebih rangkain listrik ke rangkaian yang lain, melalui suatu gandengan magnet dan berdasarkan prinsip induksi elektro magnet. Transformator digunakan secara luas, baik dalam bidang listrik mauppun elektronika. Penggunaan transformator dalam sistem tenaga memungkinkan terpilihnya tegangan yang sesuai, dan ekonomis untuk tiap-tiap keperluan, misal kebutuhan akan tegangan tinggi untuk pengiriman energi jarak jauh.

\section{PMT KOPEL SEBAGAI MEDIA PENGALIHAN BEBAN}

Dalam memparallel trafo ada beberapa kriteria yang perlu diketahui antara lain ratio tegangan transformator, persen impedansi transformator, rating KVA transformator, polaritas, urutan fasa dan sudut pergeseran fasa.

\section{Ratio Tegangan Transformator}

Salah satu kriteria yang harus diketahui yaitu ratio tegangan dari kedua transformator. Dimana ratio tegangan didapat dari perbandingan antara jumlah kumparan primer dan sekunder. Sehingga dalam pengoperasiannya besar tegangan srkunder dapat diatur dengan mengubah jumlah belitan melalui tap changer.

\section{Persen Impedansi Transformator}

Apabila transformator memiliki persen impedansi yang serupa maka beban akan terbagi sesuai dengan rating KVA trafo tersebut. Sedangkan bila nilai reaktansi dan resistansi berbeda maka akan menyebabkkan trafo-trafo tersebut akan bekerja pada nilai power faktor yang berbeda, sehingga menyebabkan pembebanan yang tidak merata. 


\section{Rating KVA Tranformator}

Apabila dua buah transformator yang memiliki rating $\mathrm{kVA}$ yang sama dihubungkan secara paralel maka akan menyebabkan beban akan terbagi sama rata, dengan catatan impedansi dan ratio tegangan memiliki nilai yang sama. Sehingga apabila melakukan kopel busbar maka akan menyebabkan jumlah seluruh beban pada kedua transformator akan dibagi merata. Sehingga dapat di perhitungkan beban berdasarkan pembacaan meter sebelumnya.

Namun apabila rating kVA dari dua buah transformator yang hendak di kopel memiliki perbedaan rating $\mathrm{kVA}$ maka pada prakteknya beban akan terbagi sesuai dengan rating kVAnya.

\section{Polaritas}

Masing-masing ujung primer dari suatu transformator satu fasa polaritasnya selalu bergantian pada waktu bekerja. Hal yang sama juga terjadi pada kumparan sekunder. Polaritas perlu diketahui untuk membuat sambungan-sambungan pada transformator (yang dimaksud disini adalah polaritas sesaat). Polaritas dari suatu transformator ditentukan oleh arah lilitannya.

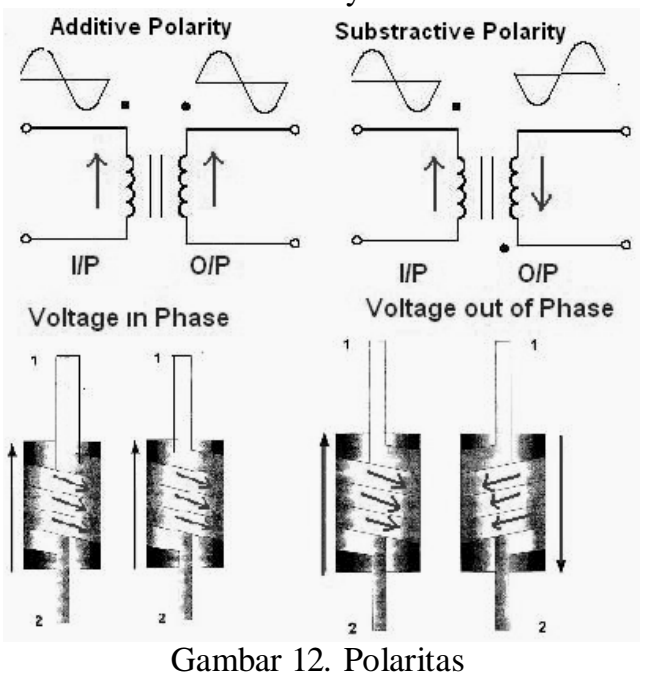

\section{Urutan Fasa}

Urutan fasa dari kedua buah transformator yang hendak dikopel harus identik. Hal ini ini dapat dilakukan dengan menghubungkan phasa R,S, dan $\mathrm{T}$ pada hubungan yang tepat. Apabila urutan fasa tidak tepat maka setiap putaran akan menyebabkan hubung singkat.

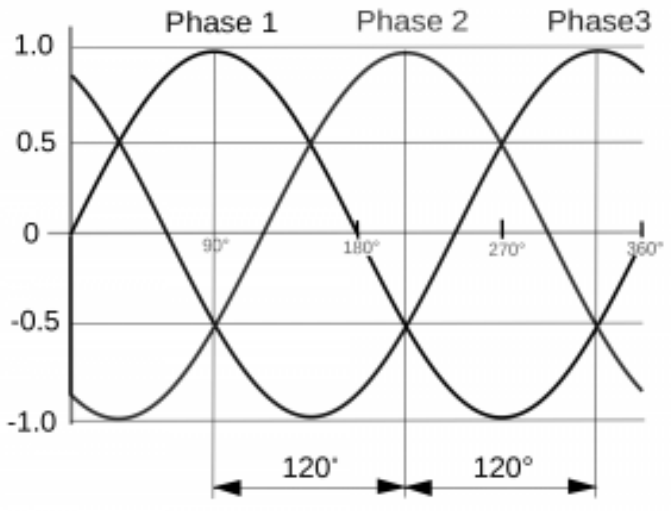

Gambar 13. Urutan fasa

\section{Sudut Pergeseran Sudut Fasa}

Trafo 3 fasa dengan 2 belitan memliki beberapa macam konfigurasi belitan. Apabila dilihat dari jenis penyusunan belitan antar fasa maka ada dua macam tipe belitan yaitu belitan Wye (star) dan belitan delta. Sedangkan berdasarkan pergeseran sudut fasa antara arus pada kumparan primer dan kumparan sekunder maka di bagi menjadi 4 grup yaitu :

- Group 1: Zero phase displacement (Yy0, Dd0, Dz0)

- Group 2:180 phase displacement (Yy6, Dd6, Dz6)

- Group 3: $-30^{\circ}$ phase displacement (Yd1, Dy1, Yz1)

- Group 4: $+30^{\circ}$ phase displacement (Yd11, Dy11, Yz11)

Pada pengkopelan sebaiknya kedua buah trafo memiliki jenis belitan dan pergeseran fasa yang identik, akan tetapi bila jenis belitan tidak sama maka dapat dilakukan asal masih dalam satu group.

\section{PMT KOPEL PADA GI SAYUNG}

Kubikel yang digunakan pada Gardu Induk Sayung adalah merk ABB, Merlin Gerlin, dan Siemens. Sehingga dalam pengoperasiannya perlu digunakan interface karena posisi busbar yang berbeda. Selain itu juga digunakan interface busbar dengan kabel power yang menghubungkan antara kubikel merk ABB dengan kubikel kopel dengan menggunakan kabel power. 


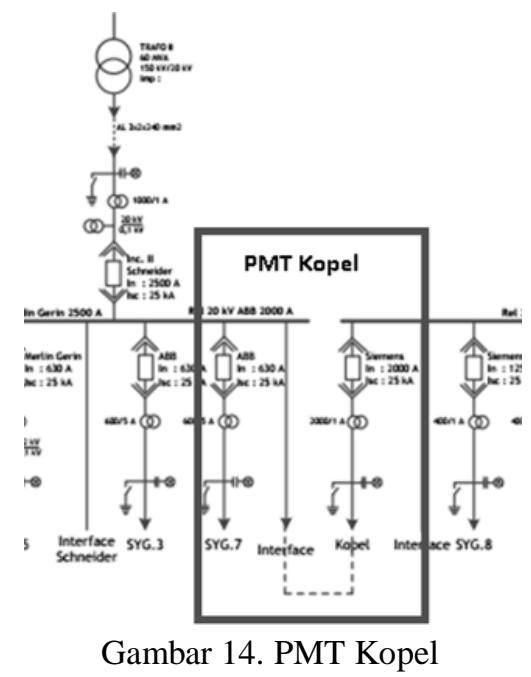

Data Trafo Gardu Induk Sayung dapat dilihat pada daftar berikut ini.

- Trafo I

$\begin{array}{cll}\text { o } & \text { Merk } & : \text { ABB } \\ \text { o } & \text { Rating KVA } & : 30 \text { MVA } \\ \text { o } & \text { Ratio Tegangan } & : 150 / 20 \\ \text { o } & \text { Ratio Arus } & : 116 / 866 \\ \text { o } & \text { Impedansi } & : 12,78 \% \\ \text { o } & \text { Vektor } & : \text { Ynyn0(d1) }\end{array}$

- $\quad$ Trafo II

$\begin{array}{lll}\text { o } & \text { Merk } & : \text { UNINDO } \\ \text { o } & \text { Rating KVA } & : 60 \text { MVA } \\ \text { o } & \text { Ratio Tegangan } & : 150 / 20 \\ \text { o } & \text { Ratio Arus } & : 230.9 / 1732 \\ \text { o } & \text { Impedansi } & : 12,50 \% \\ \text { o } & \text { Vektor } & : \text { Ynyn0 +d }\end{array}$

- $\quad$ Trafo III

$\begin{array}{lll}\text { o } & \text { Merk } & \text { : SIEMIENS } \\ \text { o } & \text { Rating KVA } & : 60 \text { MVA } \\ \text { o } & \text { Ratio tegangan } & : 150 / 20 \\ \text { o } & \text { Ratio arus } & : 230.9 / 1732 \\ \text { o } & \text { Impedansi } & : 13.1 \% \\ \text { o } & \text { Vektor } & : \text { Ynyn0(d1) }\end{array}$

Nilai seting OCR kubikel kopel pada gardu induk sayung dapat dilihat pada daftar berikut ini.

- Incoming trafo I

$\begin{array}{lll}\mathrm{o} & \mathrm{I}> & : 300 \mathrm{~A} \\ \mathrm{o} & \mathrm{Tms} & : 0.47 / \mathrm{si} \\ \mathrm{o} & \mathrm{I}>> & : 2300 \mathrm{~A} \\ \mathrm{o} & \mathrm{t} & : 0.4 \mathrm{dtk}\end{array}$

- Incoming trafo II
o I $>\quad: 700 \mathrm{~A}$
o Tms :0.45/si
o I $>\quad: 5200 \mathrm{~A}$
o $\mathrm{t} \quad: 0.4 \mathrm{dtk}$

- Incoming trfo III
o I $>$
: $700 \mathrm{~A}$
o Tms :0.45/si
o I $>\quad: 5200 \mathrm{~A}$
$0 \mathrm{t} \quad: 0.4 \mathrm{dtk}$

Adapun setting pmt kopel adalah sebagai berikut :

$\begin{array}{lll}\text { - } & \text { OCR TD } & : 2000 \mathrm{~A} \\ \text { - Tms } & : 0.15 / 51 \\ \text { - } & \text { OCR Ins } & : 6000 \mathrm{~A} \\ \text { - } \mathrm{T}>> & : 0.2 \mathrm{dtk} \\ \text { - } & \text { GFR TD } & : 400 \\ \text { - } & \text { Tms } & : 0.3 / 51 \\ \text { - } & \text { GFR Inst } & : 4700 \mathrm{~A} \\ \text { - } & \mathrm{T}>> & : 0.2 \mathrm{dtk}\end{array}$

Spesifikasi Kubikel Kopel pada Gardu Induk Sayung adalah sebagai berikut.

- Merk

: Siemens

- $\quad$ Type

: 3АH5284-6

- Inominal

: 2500

- Tegangan Kerja

: $24 \mathrm{KV}$

- I sc

: $25 \mathrm{kA}$

- Media Interupter

: Vacuum

- Nomor seri 3AH52/00002434

Perhitungan Beban Gardu Induk Sayung

\section{GRAFIK BEBAN KETIKA} DILAKUKAN KOPEL

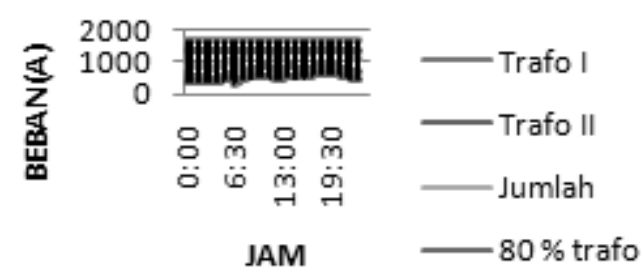

Gambar 15. Grafik beban trafo

Dari Gambar 15 dapat dilihat bahwa jumlah beban dari kedua buah trafo akan melebihi dari 80 $\%$ kemampuan trafo pada beban puncak malam. Oleh karena itu pengalihan beban hanya dapat dilakukan dari pagi hingga pukul 16.00.

\section{Kriteria Kopel Trafo II dan III pada Gardu Induk Sayung}

Seperti yang sudah dijelaskan pada bab III tentang pentingnya memenuhi kriteria dalam kopel trafo, maka perlu diketahui keadaan pada Gardu Induk Sayung.

\section{Impedansi}

Dari data trafo yang sudah disebutkan diatas dapat diketahui selisih impedansi dari kedua transformator.

Trafo II : $12.5 \%$

Trafo III :13.1\%

Sehingga selisih impedansi di atas tidak melebihi $10 \%$, sehingga kedua trafotersebut dapat melakukan pengalihan beban. 


\section{Polaritas}

Dikarenakan jenis belitan pada kedua transformator sama, serta kedua transformator tersebut memiliki sumber yang sama, maka keluaran daari kedua transformator tersebut memiliki polaritas yang sama.

\section{Urutan Fasa}

Mengenai urutan fasa, karena urutan fasa ditentukan oleh penyambungan dua buah busbar ketika pemasangan kubikel, sehingga dapat dilakukan pengalihan beban.

\section{Pergeseran Fasa}

Keluaran dari kedua buah transformator tidak mengalami pergeseran fasa dikarenakan kedua transformator tersebut memiliki hubungan belitan yang sama yaitu YnYn. Oleh sebab itu maka dapat dilakukan pengalihan beban antara trafo III dan trafo II.

\section{Pelaksanaan Pengalihan Beban dengan Menggunakan Kubikekl Kopel pada Gardu Induk Sayung}

Adapun urutan pengoperasian PMT kopel untuk pengalihan beban adalah sebagai berikut :

- Melakukan perhitungan beban pada kedua buah trafo

- Melakukan penyamaan tegangan pada kedua buah busbar

Tabel 1. Tegangan Pada jam 07.00

\begin{tabular}{|c|c|c|c|}
\hline \multirow{2}{*}{ Jam } & \multicolumn{2}{|c|}{ Trafo } & \multirow{2}{*}{$\begin{array}{c}\text { Selisih } \\
\text { Tegangan }\end{array}$} \\
\hline & I & II & \\
\hline 07.00 & $21.09 \mathrm{kV}$ & $20.95 \mathrm{kV}$ & $0.14 \mathrm{kV}$ \\
\hline
\end{tabular}

Dari tabel 1 dapat diketahui bahwa selisih tegangan antara trafo II dan trafo III tidak jauh berbeda, sehingga dapat langsung dilakukan kopel.

Apabila ada perbedaan tegangan yang sangat tinggi, maka sebelum melakukan pengalihan beban dilakukan melakukan penyamaan tegangan dua buah busbar yang hendak di kopel. Hal ini dilakukan dengan cara menyamakan posisi tap changer agar tegangan sekunder trafo sama. Apabila menggunakan OLTC maka perlu melakukan pengaturan pada AVR atau dengan cara mengubah setting tap changer menjadi operasi manual. Setelah proses pengkopelan selesai maka tap changer dapat dikembalikan pada posisi otomatis.

\section{Memasukkan PMT kopel}

Dalam melakukan pemasukan PMT kopel dilakukan dengan cara manual yaitu dengan cara memutar saklar pada low voltage kompartemen.

\section{Melepas PMT Incoming}

Setelah PMT kopel dipastikan masuk dengan cara mengamati meter sudah menunjukkan besaran, langkah berikutnya yaitu melepas PMT Incoming. Karena PMT incoming tidak terintegrasi SCADA sehingga melakuan pelepasan incoming dengan cara manual. Yaitu dengan cara memutar saklar saklar pada switch open/close. Waktu maksimal dua menit, karena apabila lebih dari itu maka pembebanan pada transformator tidak merata sehingga ditakutkan akan terjadi trip pada PMT Incoming.

Mengembalikan posisi OLTC pada posisi otomatis Setelah proses pelepasan PMT incoming selesai maka posisi OLTC perlu dikembalikan pada keadaan otomatis untuk menjaga tegangan tidak mengalami perubahan yang cukup besar, hal ini dilakukan apabila pada saat proses penyamaan tegangan merubah posisi OLTC menjadi posisi manual.

\section{Mencatat beban pada kubikel incoming}

Setelah proses pengalihan selesai maka perlu di catat besar beban pada incoming. Hal ini bertujuan untuk memastikan proses pengalihan beban berhasil.

Tabel 2. Beban Jam 07.00

\begin{tabular}{llll}
\hline Keadaan & INC II & INC III & Kopel \\
\hline $\begin{array}{l}\text { Sebelum di } \\
\text { kopel }\end{array}$ & $372 \mathrm{~A}$ & $385 \mathrm{~A}$ & $0 \mathrm{~A}$ \\
$\begin{array}{l}\text { Sesudah } \\
\text { dikopel }\end{array}$ & $759 \mathrm{~A}$ & $0 \mathrm{~A}$ & $354 \mathrm{~A}$ \\
\hline
\end{tabular}

Sedangkan untuk penormalan jaringan adalah sebagai berikut :

- Melakukan penyamaan tegangan

Tabel 3 Tegangan Pukul 16.00

\begin{tabular}{cccc}
\hline \multirow{2}{*}{ Jam } & \multicolumn{2}{c}{ Trafo } & $\begin{array}{c}\text { Selisih } \\
\text { Tegangan }\end{array}$ \\
\cline { 2 - 3 } 16.00 & $\begin{array}{c}21.33 \\
\mathrm{kV}\end{array}$ & $\begin{array}{c}21.26 \\
\mathrm{kV}\end{array}$ & $0.07 \mathrm{kV}$ \\
\hline
\end{tabular}

Sebelum melakukan penormalan harus melakukan penyamaan tegangan antara incoming dengan busbar yang sedang di kopel. Karena tegangan antar busbar dengan incoming tidak melebihi $0.5 \mathrm{kV}$ sehingga dapat langsung dilakukan kopel tanpa memposisikan OLTC pada keadaan manual.

- Memasukkan PMT Incoming

Setelah tegangan tersebut masuk sesuai ketentuan maka dapat dilakukan pemasukan PMT incoming dengan cara local. Dengan menggunakan switch pada panel kontrol PMT.

- $\quad$ Melepas PMT kopel

Setelah PMT Incoming masuk sempurna maka dapat dilakukan pelepasan PMT kopel. Yaitu dengan menggunakan switch pada panel kontrol PMT kopel. 
- Mengembalikan posisi OLTC pada posisi otomatis

Setelah proses pelepasan PMT kopel selesai maka OLTC perlu dikembalikan pada posisi otomatis, apabila pada saat melakukan pengalihan beban melakukan penyamaan tegangan dengan memposisikan OLTC pada keadaan manual.

- Mencatat besar beban pada kedua incoming Untuk memastikan keadaan sudah kembali normal maka perlu dicatat beban pada kedua incoming.

Tabel 4. Beban Pukul 16.00

\begin{tabular}{lllcl}
\hline Keadaan & INC & INC & Kopel & \\
& II & III & & \\
\hline Sebelum & 1273 & $0 \mathrm{~A}$ & $488 \mathrm{~A}$ & \\
di kopel & A & & & \\
Sesudah & 785 & 490 & 0 & $\mathrm{~A}$ \\
dikopel & A & A & & \\
\hline
\end{tabular}

Kelebihan Menggunakan Kubikel Kopel

- Lebih cepat dalam melakukan pengalihan beban trafo karena tidak perlu mengirim petugas untuk memanuver jaringan tegangan menengah.

- Lebih mudah dalam pengerjaanya.

- $\quad$ Tidak memerlukan personil yang banyak.

Kekurangan Menggunakan Kubikel Kopel

- Harus mengetahui beban pada satu hari.

- Harus memenuhi persyaratan pengkopelan trafo.

Apabila ada gangguan pada busbar maka menyebabkan seluruh feeder yang sedang di kopel akan padam karena incoming trip.

\section{KESIMPULAN}

Dari pembahasan di atas dapat ditarik kesimpulan sebagai berikut :

- Dalam proses pengalihan beban trafo dua atau tiga gardu induk sayung hal utama yang harus diperhatikan yaitu melakukan penyamaan tegangan serta melakukan perhitungan beban. Hal ini dimaksudkan agar tidak terjadi beban lebih pada trafo.

- Pada Gardu Induk Sayung, syarat-syarat parallel trafo sudah di penuhi, karena memiliki polaritas, urutan fasa, serta pergeseran fasa yang sama. Sedangakan impedansinya tidak melebihi dari ketentuan, sehingga dapat dilakukan kopel. Untuk ratio tegangan sendiri dapat disesuaikan dengan menggunakan OLTC.

- Dalam pengoperasian peralatan gardu induk sisi $20 \mathrm{kV}$, sebuah pemutus tenaga dapat difungsikan sebagai media pengalihan beban. Dimana PMT difungsikan sebagai penghubung dua buah busbar, sehingga apabila hendak melakukan pengalihan beban maka kedua buah busbar $20 \mathrm{kV}$ dapat di hubungkan lalu melepas salah satu PMT incoming. Sedangkan PMT yang digunakan yaitu PMT dengan kemampuan 2500 A yang mana mampu mengalirkan arus dari sebuah busbar.

- Dari pehitungan arus dapat diketahui, dalam melakukan pengalihan beban dengan menggunakan PMT kopel pada Gardu Induk Sayung hanya dapat dilakukan pada pagi hari hingga sore hari pukul 16.00. Hal ini dikarenakan pada beban puncak sore beban kedua buah trafo melebihi $80 \%$ kapasitas sebuah trafo 60 MVA.

\section{DAFTAR PUSTAKA}

1. Jignesh., Parmar, 2012, Parallel Operation of transformer.

2. Kadir, Abdul. 1981. Transformator. Jakarta : Pradnya Paramita

3. Kadir, Abdul. 1986. Pengantar Teknik Tenaga Listrik. Jakarta : LP3ES

4. Sulasno. 2001. Distribusi Tenaga Listrik. Semarang : Badan Penerbit Universitas Diponegoro

5. Sulasno. 1993. Analisa Sistem Tenaga Listrik. Semarang : Satya Wacana

6. Zuhal. 1988. Dasar Teknik Tenaga Listrik dan Elektronika Daya. Jakarta : Gramedia Pustaka Utama 